\title{
Indicator of Myocardial Ischemia Based on the Mean Power of ECG Low Frequency Content: Comparison with ST Segment Trend
}

\author{
A Gutiérrez, G Zarco* \\ Centro de Investigación en Computación del IPN, Mexico City, Mexico \\ *Instituto Nacional de Cardiología Ignacio Chávez, Mexico City, Mexico
}

\begin{abstract}
In order to cause myocardial ischemia, the left anterior descending coronary artery was occluded and released two times in twelve dogs. The occlusion release times and the ECG were recorded.

Spectral content in the range of 1 to $10 \mathrm{~Hz}$ was obtained by means of a digital filter. After filtering, the mean power was determined and plotted in normalized trend curves. Averaged beats were calculated, one per epoch per lead, and used to obtain ST level trend plots. The events true-occlusion, late true-occlusion, falseocclusion, true-reperfusion and false-reperfusion were defined according to the arterial status and then counted.

It was concluded that the indicator based on ECG low-frequency content can not replace the ST segment trend. However, it should be suitable to improve decision - making when an alternative therapy could be necessary.
\end{abstract}

\section{Introduction}

Changes to negative polarity in $\mathrm{T}$ wave, variations in ST level following and substituting negative $\mathrm{T}$ wave, morphological changes in QRS complex and arrhythmia occurrence, they all represent a sequence of electrocardiographic events involved during a coronary occlusion [1,2]. Typically, the arterial reperfusion may cause a gradual reversion to electrocardiographic basal conditions $[1,2]$. The use of thrombolytic agents may induce reperfusion and accelerate the return to electrocardiographic basal conditions [3].

Daily, ECG morphological changes are used to determine myocardial ischemia and the first trials to evaluate reperfusion therapies by means of ECG emerged from the application of continuous monitoring technique. Several studies have demonstrated the utility of time domain monitoring of the ST segment [3-10], QRS vector difference [4,10-13] and heart rate variability[14].

Because some problems of specificity and sensitivity remain in these continuous monitoring techniques, some other domains have been explored. At present, heart rate variability is expressed as the relationship between their low and high frequency contents [15-17]. It is pretended to improve ST segment monitoring using wavelet $[18,19]$ and Karhunen-Loève transforms [20,21], among others. Wavelet transform has been also used to identify ECG fiducial points and patterns [22-24], but unfortunately these three studies are not related with reperfusion evaluation.

On the other hand, the variety in recording techniques used by different researchers, (including errors in bandwidth), the lacking in uniform criteria to classify ischemic changes in electrocardiogram, the diversity in agents used for reperfusion (different thrombolytic agents with or without adjuvant drugs, angioplasty and coronary bypass) and the variety in validation techniques (TIMI grade, enzymatic levels, mortality rate in different terms and ventricular ejection fraction), do not permit to find out if the added techniques indeed improve the performance of reperfusion indicators.

Considering the facts above described, an indicator of myocardial ischemia based on the mean power of ECG low frequency content was previously developed [25], and now compared with ST segment trend.

\section{Method}

\subsection{ECG recording}

In order to obtain similar records to those obtained from an infarct - thrombolysis situation, the next experiment was developed.

In twelve anesthetized and ventilated dogs $(18-25$ $\mathrm{Kg}$ ) the left anterior descending coronary artery was occluded and released according to the Harris technique. The first occlusion lasted $5 \mathrm{~min}$. A 20 min recovery period was allowed before a second occlusion was induced. This occlusion lasted from 20 to $120 \mathrm{~min}$, different for each animal.

Leads II and III were obtained, as well as epicardial records in those zones where necrosis, injury, ischemia 
and normal records were expected, three records per zone.

The used bandwidth was from 0 to $180 \mathrm{~Hz}$. The fourteen leads were simultaneously amplified and digitized (540 samples per second, 12 bits per sample). Every 30 s, 28 s epochs were saved on a hard disk.

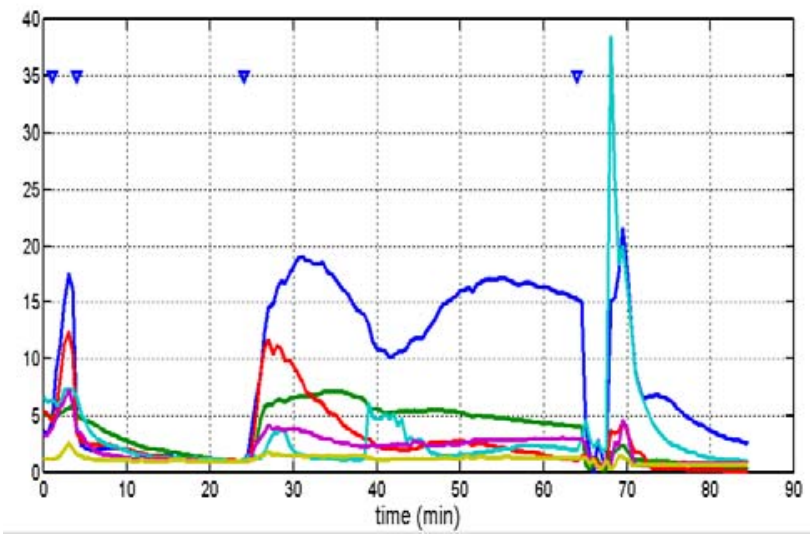

Figure 1. Normalized mean - power of ECG low frequency content. Different curves correspond to different myocardial zones. Coronary occlusions are represented by the first and third triangular marks, the second and fourth ones correspond to releases. The values just before the second occlusion were used as reference during the normalization. The sudden decrement and increment after the second release were caused by fibrillation and recorder disconnection, respectively.

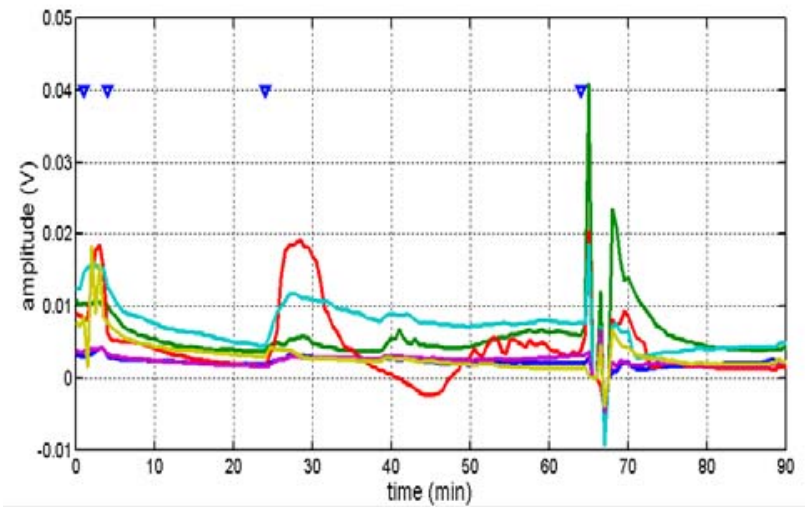

Figure 2. ST segment trend plot for the same experiment illustrated in figure 1.

\subsection{ECG processing}

Spectral content in the range of 1 to $10 \mathrm{~Hz}$ was obtained by means of a $3^{\text {rd }}$ order Butterworth digital filter. Per epoch, and after filtering, the mean power was determined and plotted in normalized trend curves, see figure 1. Values in a time showing normal circulation were used as reference in normalization process.

In order to determine the ST segment trend plots, the QRS complexes were detected and classified (by means of the correlation coefficient). Using only the normal QRS complexes an averaged beat was obtained per epoch per lead. The ST level was measured $65 \mathrm{~ms}$ after the R wave in these beats. Figure 2 shows a ST segment trend plot.

\subsection{Events definition and counting}

A threshold was established for each indicator, $3 \mathrm{mV}$ for ST trend and 3 for normalized ECG mean power. When the indicator value exceeded this threshold an occlusion was considered. The following events were also defined and counted:

True occlusion. An indicator exceeds the threshold two or more consecutive times (equivalent to 1 or more min of signal) while the coronary occlusion is sustained.

Late true occlusion. It is a true occlusion that exceeds the threshold 5 min after the beginning of the occlusion.

False occlusion. An indicator exceeds the threshold two or more consecutive times while the coronary artery is not occluded. It was determined only when occurred between the two experimental occlusions.

True reperfusion. After a true occlusion or a late true occlusion and the coronary release, the indicator returns to under threshold values.

False reperfusion. After a true occlusion or a late true occlusion and while the coronary occlusion is sustained the indicator returns to under threshold values.

\section{Results}

Two animals died before the experiment finished, therefore, the next data correspond to 10 cases.

The table 1 shows the occurrence of the occlusions and reperfusions events. The event count was made considering separately each captured lead, this because in a clinical environment usually only a few leads are available.

Table 1. Events counted for each indicator.

\begin{tabular}{|l|c|c|}
\hline & ST segment trend & $\begin{array}{c}\text { Mean power of } \\
\text { ECG LF content }\end{array}$ \\
\hline True occlusion & 77 & 60 \\
\hline $\begin{array}{l}\text { Late } \\
\text { true occlusion }\end{array}$ & 8 & 12 \\
\hline False occlusion & 4 & 4 \\
\hline True reperfusion & 47 & 48 \\
\hline False reperfusion & 28 & 16 \\
\hline
\end{tabular}




\section{Discussion}

Because of the experimental conditions, there are low levels of noise in the records, there is not bundle branch blocks, etc. In these conditions, the simple approach used for ST measurements results proper.

As compared with clinical values, the point selected for the ST level measurement and the ST threshold, could seem odd. They were selected for dog - epicardial records.

It was observed that the ST segment trend detected more occlusions (77 true +8 late true against $60+12$ of the man power), but on the other hand, it also showed more false reperfusions (28 against 16 ). Both indicators registered four false occlusions, all of it corresponding to the same event. It leads to think over the possibility of a true occlusion, and therefore, about the need of a direct method for the coronary flux measurement during the experiments.

When prolonged occlusions occurred (as the second one in each experiment), the mean power of ECG low frequency content showed less false reperfusions. However, some times it also diminishes when the occlusion remains for a long time, probably because of the collateral circulation.

\section{Conclusions}

Taking into account that the mean power of ECG low frequency content detected better the reperfusion status, it should be suitable to improve decision - making when an alternative therapy could be necessary.

\section{Acknowledgements}

The authors thank the collaboration of Dr. Gustavo Pastelín and Mr. Saúl Carreón. IPN.

\section{References}

[1] Katz AM, The Ischemic Heart. In: Physiology of the heart Second Edition. Raven Press, 1992. Chapter 24.

[2] Sodi D, Medrano GA, Bisteni A, Ponce de León J. Generalidades acerca de los tejidos isquémico, lesionado y muerto. In: Electrocardiografía Clínica Análisis Deductivo. Méndez Editores, México, 1998. Chapter 8.

[3] Langer A, Krucoff MW, Klootwijk P. Noninvasive assessment of speed and stability of infarct-related artery reperfusion: results of the GUSTO ST segment monitoring study. Global Utilization of Streptokinase and Tissue Plasminogen Activator for Occluded Coronary Arteries. J Am Coll Cardiol. June 1995. 25. 7. 1552-7.

[4] Krucoff MW, Green CE, Satler LF, Miller FC, Pallas RS,
Kent KM, Del Negro AA, Pearle DL, Fletcher RD, Rackley CE. Noninvasive Detection of Coronary Artery Patency Using Continuous ST-Segment Monitoring. Am J Cardiol. 1986. 57. 916-22.

[5] Drew BJ, Wung SF, Adams MG, Pelter MM. Bedside diagnosis of myocardial ischemia with ST-segment monitoring technology: measurement issues for real-time clinical decision making and trial designs. J Electrocardiol. 1998. 30 Suppl. 157-65.

[6] Krucoff MW, Croll MA, Pope JE. Continuously Updated 12-Lead ST-Segment Analysis for Myocardial Infarct Artery Patency Assessment and Its Correlation with Multiple Simultaneous Early Angiographic Observations". Am J Cardiol. 1993. January 15.

[7] Klootwijk P, Langer A, Meij S, Green C, Veldkamp RF, Ross AM, Armstrong PW, Simoons ML, for the GUSTO-1 ECG-ischemia monitoring substudy. Non-invasive prediction of reperfusion and coronary artery patency by continuous ST segment monitoring in the GUSTO-1 trial. Eur Heart J. 1996. 17. 689-98.

[8] Fernandez AR, Sequeira RF, Chakko S, Correa LF, de Marchena EJ, Chahine RA, Franceour DA, Myerburg RJ. ST segment tracking for rapid determination of patency of the infarct-related artery in acute myocardial infarction. J Am Coll Cardiol. 1995. 26(3). 675-83.

[9] Buszman P, Szafranek, Kalarus Z, Gasior M. Use of changes in ST segment elevation for prediction of infarct artery recanalization in acute myocardial infarction. Eur Heart J,. 1995. 16. 1207-14.

[10] Dellborg M, Steg PG, Simoons M, Dietz R, Sen S, van den Brand M, Lotze U, Hauck S, van den Wieken R, Himbert D, Svensson AM, Swedberg K. Vectorcardiographic monitoring to assess early vessel patency after reperfusion therapy for acute myocardial infarction. Eur Heart J. Jan 1995. 16(1). 21-9.

[11] Dellborg M, Riha M, Swedberg K, for the TEAHAT Study Group. Dynamic QRS-Complex and ST-Segment Monitoring in Acute Myocardial Infarction During Recombinant Tissue-Type Plasminogen Activator Therapy. 1991. Am J Cardiol. 67. 343-9.

[12] Dellborg M, Topol EJ, Swedberg K. Dynamic QRS complex and ST segment vectorcardiographic monitoring can identify vessel patency in patients with acute myocardial infarction treated with reperfusion therapy. Am Heart J. 1991. 122. 4. 943-8.

[13] Wagner NB, Sevilla DC, Krucoff MW, Lee KL, Piper KS, Kent KK, Bottner RK, Selvester RH, Wagner GS. Transient Alteration of the QRS Complex and ST Segment During Percutaneous Transmural Ballon Angioplasty of the Left Anterior Descending Coronary Artery. Am J Cardiol. 1988. 62. 1038-42.

[14] Kleiger RE, Miller JP, Bigger JT, Moss AJ, and the Multicenter Post-Infarction Research Group. Decreased Heart Rate Variability and Its Association with Increased Mortality After Acute Myocardial Infarction. Am J Cardiol. 1987. 59. 256-62.

[15] Bonnemeier H, Hartmann F, Wiegand UK, Irmer C, Kurz T, Tolg R, Katus HA, Richardt G. Heart rate variability in patients with acute myocardial infarction undergoing primary coronary angioplasty. Am J Cardiol Apr 12000. 85. 7. 815-20. 
[16] Hohnloser SH, Klingenheben T, Zabel M, Schopperl M, Mauss O. Prevalence, characteristics and prognostic value during long-term follow-up of nonsustained ventricular tachycardia after myocardial infarction in the thrombolytic era. J Am Coll Cardiol. Jan 1999. 33. 7. 1895-902.

[17] Singh N, Mironov D, Armstrong PW, Ross AM, Langer A: for the GUSTO ECG Substudy Investigators. Heart Rate Variability Assessment Early After Acute Myocardial Infarction. Circulation. April 1 1996. 93. 7. 1388-95.

[18] Gramatikov B, Yi-chun S, Rix H, Caminal P, Thakor NV. Multiresolution Wavelet Analysis of the Body Sourface ECG Before and After Angioplasty. Ann Biomed Eng. 1995. 23. 553-61.

[19] Sahambi JS, Tandon SN, Bhatt RKP. Wavelet based STsegment analysis. Med Biol Eng Comput 1998. 36. 568-72.

[20] Laguna P, Moody GB, García J, Goldberger AL, Mark RG. Analysis of the ST-T complex of the electrocardiogram using the Karhunen - Loève transform: adaptive monitoring and alternans detection. Med Biol Eng Comput. 1999. 37. 175-89.

[21] Garcia J, Lander P, Sornmo L, Olmos S, Wagner G, Laguna P. Comparative study of local and KarhunenLoeve-based ST-T indexes in recordings from human subjects with induced myocardial ischemia. Comput Biomed Res. 1998. 31.4. 271-92.
[22] Li C, Zheng C, Tai C. Detection of ECG Characteristic Point Using Wavelet Transforms. IEEE Trans Biomed Eng. 1995. 42. 1.

[23] Senhadij L, Carrault G, Bellanger JJ, Passariello G. Comparing Wavelet Transforms for Recognizing Cardiac Patterns. IEEE Eng Med Biol. March/April 1995. 167-73.

[24] Sahambi JS, Tandon SN, Bhatt RKP. Using Wavelet Transforms for ECG Characterization. IEEE Eng Med Biol. January/February 1997. 77-83.

[25] Gutiérrez A, Hernández PR, Pastelín G. ECG Mean-Power as Primary Indicator of Myocardial Ischemia. Computers in Cardiology 2001;28:369-372.

Address for correspondence.

Alfonso Gutiérrez

Centro de Investigación en Computación, IPN.

Av Juan de Dios Bátiz s/n

Col. Nueva Industrial Vallejo

México D.F. CP. 07738

México

E-mail: alfonso_gamx@yahoo.com.mx 